\title{
Azithromycin in COVID-19 Patients: Pharmacological Mechanism, Clinical Evidence and Prescribing Guidelines
}

\author{
Janet Sultana ${ }^{1}$ - Paola Maria Cutroneo ${ }^{1}$. Salvatore Crisafulli ${ }^{1}$. Gabriele Puglisi ${ }^{1}$. Gaetano Caramori ${ }^{1}$. \\ Gianluca Trifirò ${ }^{1}$ (1)
}

Published online: 21 July 2020

(c) Springer Nature Switzerland AG 2020

\begin{abstract}
The global COVID-19 pandemic has led to a race to find medications that can improve the prognosis of the disease. Azithromycin, in association with hydroxychloroquine or chloroquine, has been proposed as one such medication. The aim of this review is to describe the pharmacological mechanism, clinical evidence and prescribing guidelines concerning azithromycin in COVID-19 patients. There is weak evidence on the antiviral and immunomodulating effects of azithromycin, which in addition is not based on results from COVID-19 patients specifically. Therefore, this antibacterial should be considered only as empirical treatment of community-acquired pneumonia (CAP), although not all current treatment guidelines are in agreement. After the initial expectations raised by a small trial, more recent evidence has raised serious safety concerns on the use of hydroxychloroquine or chloroquine with azithromycin to treat COVID-19 patients, as all these drugs have arrhythmogenic potential. The World Health Organization has not made recommendations suggesting the use of azithromycin with hydroxychloroquine or chloroquine as treatment for COVID-19, but some national organisations have taken a different position, recommending this as first-line treatment. Several scientific societies, including the American College of Cardiology, have cautioned about the risks of this treatment in view of the lack of evidence concerning its benefits.
\end{abstract}

\section{Key Points}

Azithromycin has been proposed as a drug to treat COVID-19 infection, although this drug has torsadogenic potential which is cause for concern, especially if concomitantly administered with hydroxychloroquine/ chloroquine

There is currently no evidence to support the efficacy of azithromycin treatment in COVID-19 infection, as completed trials are methodologically flawed and underpowered

Major public health organisations, drug regulatory agencies and scientific societies do not recommend the use of azithromycin as a drug to treat COVID-19 infection, unless bacterial superinfections occur

Gianluca Trifirò

trifirog@unime.it

Department of Biomedical and Dental Sciences and Morphofunctional Imaging, University of Messina, Messina, Italy

\section{Introduction}

The global COVID-19 pandemic has led to $9,400,295$ infected patients and 482,468 deaths worldwide between 31st December 2019 and 25th June 2020, according to the European Centre for Disease Control [1]. This public health emergency has triggered a race to find medications to improve the prognosis of disease. In turn, this has led to a tug of war between proponents of the conservative approach of not using medications in COVID-19 infection unless their risk-benefit profile has been scientifically proven and the proponents of the non-conservative approach proposing to offer new treatment even in absence of strong scientific evidence, on the basis of clinical intuition or in vitro findings only [2]. Making such decisions under the pressure of a pandemic is not easy. On one hand, scientific evidence is needed to confirm that the benefits of treatment outweigh the risks, but on the other hand, the clinical trials needed to do this can be difficult to plan, implement and ultimately generate robust scientific evidence in a short time. There is currently great interest in drug repurposing or repositioning to manage COVID-19 infection, that is, the evaluation of the usefulness of a drug for an indication different to that for 
which it was marketed. One such case is the use of the macrolide azithromycin, often in association with the diseasemodifying anti-rheumatic drugs hydroxychloroquine/chloroquine, in COVID-19 patients. It is important to critically analyse the available evidence in favour or against the use of azithromycin, in particular in association with hydroxychloroquine/chloroquine, in COVID-19 patients, both in terms of benefit and risk. At present, the World Health Organization (WHO) as well as the European Medicines Agency (EMA) have indicated the lack of evidence supporting the efficacy of any medication in COVID-19 [3, 4].

Clinical evidence on the antibacterial effect in community-acquired pneumonia (CAP) as well as immunomodulating and antiviral actions as a rationale for the use of azithromycin in COVID-19 are reviewed and prescribing guidelines discussed in detail. The main risks underlying the use of this antibacterial, that is, torsadogenic potential, especially in association with hydroxychloroquine/chloroquine, is also described.

\section{The Potential Role of Azithromycin in COVID-19 Infection: A Pharmacological Perspective}

The strongest evidence of effectiveness for azithromycin concerns its role as an antibacterial drug. Although there is no direct evidence of the effectiveness of azithromycin in COVID-19, some scientific bodies have suggested that the antibacterial properties of azithromycin remain clinically useful in the empirical treatment of CAP occurring in COVID-19 patients. Not all current treatment guidelines agree on azithromycin use in CAP. There is weak evidence on the antiviral and immunomodulating effects of azithromycin, which in addition was not derived from persons with COVID-19 specifically. The available evidence is discussed below.

\subsection{Antibacterial Effect in Bacterial Community-Acquired Pneumonia}

In most patients with suspected or confirmed SARS-CoV-2 infection, lung damage correlates with the severity of viral infection; however, bacterial co-infection has been reported in several patients affected by COVID-19 pneumonia [5-7]. Thus, some guidelines have been adapted in the context of the COVID-19 pandemic to promote the appropriate use of antibiotics and to delineate the role of these drugs, including azithromycin, in COVID-19 patients.

The United Kingdom's National Institute for Health and Care Excellence (NICE) has developed a guideline aiming to improve antibiotic prescribing in COVID-19 patients with concomitant bacterial CAP or hospital-acquired pneumonia
(HAP) [8]. In the absence of bacterial co-infection, antibiotic therapy is contraindicated for COVID-19 pneumonia, because it would be ineffective, considering its viral aetiology. Therefore, according to NICE the use of antibiotics should be limited only to the management of those situations in which bacterial pulmonary co-infections are suspected or confirmed. The decision-making process in choosing antibiotic therapy should be based on clinical tests, such as microbiological tests, chest imaging, complete blood count, urine tests for legionella and pneumococcal antigens. Moreover, for the treatment of severe bacterial CAP in COVID-19 patients, the NICE guideline suggests the use of clarithromycin among macrolide antibiotics, in association with co-amoxiclav, orally or intravenously, or in co-administration with cefuroxime as an alternative to co-amoxiclav. Although, in a systematic review, it was found that the clinical efficacy and number of adverse events of azithromycin was not significantly different from clarithromycin in adults with low- to moderate-severity CAP [9], azithromycin is not recommended for the treatment of CAP or HAP in the NICE guideline because its long half-life could increase the risk of antibacterial resistance [10]. However, in another guideline on the treatment of bacterial CAP in COVID-19 patients proposed by the American Thoracic Society (ATS) and Infectious Diseases Society (IDS), antibiotic macrolides are recommended as first-line therapy in combination with $\beta$-lactams in low-risk patients, and both azithromycin and clarithromycin are indicated [5].

The use of azithromycin alone to prevent bacterial coinfections in COVID-19 patients is not supported by the above-mentioned guidelines adapted for the SARS-CoV-2 pandemic. According to the NICE guidelines, antibiotic therapy should be limited only to COVID-19 patients where bacterial co-infection is suspected or confirmed [8].

\subsection{Immunomodulating Effect}

Since cytokine release syndrome (CRS), also known as cytokine storm, seems to be a major driver of mortality in COVID-19, several drugs with immunomodulating activity have been proposed as potential agents to be repurposed for the treatment of COVID-19 patients [11]. Indeed, several immunomodulatory effects of azithromycin have been found in many experimental studies [12-14]. It has been demonstrated that in mammalian cells, azithromycin influences intracellular mitogen-activated protein kinase (MAPK), in particular extracellular signal-regulated kinases $1 / 2$ (ERK1/2) and the NF- $\mathrm{KB}$ pathway downstream of ERK [12]. Because these pathways are involved in many cellular functions, including inflammatory cytokine production, cell proliferation and mucin secretion, effects on ERK1/2 and NF- $\mathrm{KB}$ can explain most of the reported 
immunomodulatory effects of the macrolides [12]. Due to these immunomodulatory effects, azithromycin has proven effective in the management of several chronic lung diseases, such as cystic fibrosis (CF), non-CF bronchiectasis, chronic obstructive pulmonary disease, chronic rhinosinusitis, sepsis and diffuse panbronchiolitis [12,13].

In murine experimental models of Pseudomonas aeruginosa lung infection and lipopolysaccharide-induced inflammation, studies described a reduction of lung leukocytes, inflammatory cytokines, levels of myeloperoxidase, tumour necrosis factor (TNF)- $\alpha$ and interleukin (IL) $-1 \beta$ and a change of macrophage activation $[12,14]$. The cytokine storm and the excessive immunological response are considered to be the main cause of morbidity and mortality in viral pneumonia caused by the severe acute respiratory syndrome (SARS) and MERS coronaviruses, as well as for SARS-CoV-2. Therefore, modulation of the inflammatory response may theoretically reduce the complications of viral pneumonia [11]. However, the use of immunomodulatory agents, such as corticosteroids, in patients with SARS has not shown significant beneficial effects [15]. However, very recently announced results from the Oxford University Recovery Trial seem to suggest that dexamethasone reduced mortality among patients receiving invasive mechanical ventilation or oxygen, but not among those not receiving respiratory support [16]. There is also no evidence that the use of azithromycin in COVID-19 mitigates the cytokine storm.

\subsection{Antiviral Effect}

Azithromycin is also thought to have antiviral properties that may work in synergy with antiviral drugs. Preclinical studies have found that this macrolide antibiotic can exert antiviral effects against Zika virus, rhinovirus and Ebola virus [17-20]. However, antiviral effects specifically in COVID-19 patients have not yet been demonstrated. Clinical studies on the use of azithromycin in patients with pneumonia caused by respiratory viruses had conflicting findings. In a multi-centre, open-label, randomised clinical trial conducted among patients with influenza A, a combination therapy of osteltamivir plus azithromycin ( $2 \mathrm{~g} /$ day, extended-release formulation) was associated with improvement of some influenza-related symptoms, but with no difference in inflammatory cytokine levels [21]; furthermore, the azithromycin dosage used in this study was higher than that recommended by the ATS guideline. There is also limited evidence concerning the usefulness of azithromycin in viral infections that are similar to COVID-19 infection. A retrospective cohort study conducted in 14 tertiary-care hospitals in five cities in Saudi Arabia from 2012 to 2018 [22] demonstrated that in 349 patients with laboratory-confirmed Middle-East Respiratory Syndrome (MERS), caused by a coronavirus similar to SARS-COV-2, treatment with macrolides ( 97 patients treated with azithromycin, 28 treated with clarithromycin and 22 treated with erythromycin) was not associated with a reduction in 90-day mortality (adjusted odds ratio 0.84 ; 95\% confidence interval (CI) 0.47-1.51; $p=0.56$ ) or improvement in MERS-CoV RNA clearance (adjusted hazard ratio 0.88 ; 95\% CI $0.47-1.64 ; p=0.68$ ). To date, there is no robust evidence on the effectiveness of azithromycin (plus hydroxychloroquine/chloroquine) for COVID-19, alone or in combination, even for the treatment of viral infections similar to SARS-CoV-2.

\section{Clinical Evidence on the Role of Azithromycin in COVID-19 Patients}

The main clinical 'evidence' concerning the benefit of azithromycin with or without hydroxychloroquine or chloroquine in COVID-19 infection comes from an open-label non-randomised trial in France recruiting 42 hospitalised persons with COVID-19 over 14 days. Patients were treated with hydroxychloroquine $600 \mathrm{mg}$ daily with add-on azithromycin $(500 \mathrm{mg}$ on day 1 followed by $250 \mathrm{mg}$ per day for the next 4 days) in six patients to prevent bacterial superinfection. The investigators found that on day 6 after enrolment, $100 \%$ of patients treated with hydroxychloroquine and azithromycin $(n=6)$ had no detectable viral load, compared with $57.1 \%$ in patients treated with hydroxychloroquine monotherapy $(n=14)$ and $12.5 \%$ in the control group $(n=16)(p<0.001)$. There are several methodological issues with this paper that have been described in detail elsewhere, including poor reporting, missing PCR data and unjustified exclusion of patients with clinically important outcomes [23]. These limitations critically affect the quality of this study, making the reliability of the results obtained questionable. A conflicting finding was reported in a recent small French study on eleven COVID-19 patients who were treated with hydroxychloroquine plus azithromycin, at the same dosage used by Gautret et al. Of these 11 patients, one died, two were transferred to intensive care and one developed a prolongation of QT interval and interrupted the treatment. By the end of the study, eight patients (73\%) were still positive for SARS-CoV-2, 5-6 days after the start of treatment [24]. Like the trial by Gautret et al., this trial was also limited by the very small population and the lack of randomisation. A recent observational study has also raised concerns about the benefits of hydroxychloroquine/chloroquine, used alone or with a macrolide, in COVID-19 patients. One study enrolled 1438 hospitalised patients with a diagnosis of COVID-19. Of these, $735(51.1 \%)$ received hydroxychloroquine plus azithromycin, 271 (18.8\%) received hydroxychloroquine alone, $211(14.7 \%)$ were treated with azithromycin alone and $221(15.4 \%)$ were treated with other drugs. Adjusted 
statistical analyses showed no significant differences in inhospital mortality for patients receiving hydroxychloroquine plus azithromycin, hydroxychloroquine alone or azithromycin alone, compared with patients receiving neither drug [25].

Major scientific societies, drug regulatory agencies and public health organisations have not recommended the use of azithromycin in COVID-19, to our knowledge. For example, the WHO and EMA have not issued any statement about the safety and efficacy of this combination in COVID-19 infection. The Italian Drug Agency (AIFA) stated that the use of azithromycin, alone or in combination with hydroxychloroquine/chloroquine, for the treatment of COVID-19 patients is not recommended, unless bacterial superinfections occur [26]. However, the benefit-risk profile of these drugs in COVID-19 patients is still coming to light. To date there are 20 ongoing clinical trials concerning the use of azithromycin, alone or in combination with other drugs, in COVID-19 registered in clinicaltrials.gov.

\section{Torsadogenic Effects of Azithromycin}

Given the limited evidence on the benefits of azithromycin (with or without hydroxychloroquine/chloroquine) in COVID-19 patients or even as a first-line agent for CAP, it is imperative to weigh its risks. Some macrolides are well known to be arrhythmogenic, notably erythromycin [27-32]. Azithromycin is believed to be one of the safest macrolides [33] but there is conflicting information on the risk of arrhythmia. At the pre-clinical level, the proarrhythmogenic effects of azithromycin were investigated in different animal models (guinea pigs, rabbits and dogs), showing that azithromycin is not associated with torsades de pointes (TdP) or early afterdepolarisations, although this drug increases QT interval and monophasic action potential duration [34-36].

Clinical studies suggest that azithromycin does not alter the risk of cardiac events as was shown in two randomised controlled trials evaluating the efficacy of antibiotic therapy with azithromycin for the secondary prevention of coronary events [37]. These results were further confirmed by two meta-analyses of randomised clinical trials showing that azithromycin was not significantly associated with either a reduction of the frequency of recurrent cardiac events [38] or with an increased risk for mortality or cardiovascular events in patients with coronary artery disease [39]. However, there are several case reports describing QT-interval prolongation [40-42], TdP [43-45] and polymorphic ventricular tachycardia [46] during treatment with azithromycin. These proarrhythmogenic effects are pharmacologically plausible [47].

Moreover, there is evidence from post-marketing surveillance data supporting concerns about the potential torsadogenic effects azithromycin. A pharmacovigilance study analysed the FDA Adverse Event Reporting System (FAERS) from 2004 to 2011 and identified a total of 203 reports of arrhythmia-related events (e.g. QT prolongation, $\mathrm{TdP}$, ventricular arrhythmia, sudden cardiac death) associated with azithromycin [48]. The public version of Eudravigilance, the European Medicines Agency's Adverse Drug Reactions (ADR) database (http://www.adrreports.eu/en/ search.html), has 188, 87 and 55 cases of QT prolongation in patients treated with azithromycin, hydroxychloroquine and chloroquine, respectively, out of a total of $12,764,15,129$ and 1644 reports for each suspected drug (Table 1). In addition, several observational studies investigated the association of cardiovascular death (as a potential consequence of QT prolongation) with azithromycin use. These studies report conflicting evidence [49-56]. There is very limited and contrasting real-world evidence concerning the risk of azithromycin use and ventricular arrhythmia [57-59].

In light of the above-mentioned data, caution is warranted if azithromycin is used concomitantly with chloroquine or hydroxychloroquine to treat COVID-19, as both drugs have known risk of TdP [60]. There is increasing and contrasting data evaluating the safety of combination therapy. A recent observational study evaluated the effects of the association of azithromycin with chloroquine or hydroxychloroquine on QT interval in 201 COVID-19 patients. Of these, ten patients (5.0\%) received chloroquine, 191 (95.0\%) were treated with hydroxychloroquine and 119 (59.2\%) also received azithromycin. The authors found that, although the maximum QT during treatment was significantly longer in the combination group compared with the monotherapy group $(470.4 \pm 45.0 \mathrm{~ms}$ vs $453.3 \pm 37.0 \mathrm{~ms} ; p=0.004)$, no instances of TdP or arrhythmogenic death were reported [61]. However, these findings have been refuted by several recent studies evaluating the effects of this association on QT interval in COVID-19 patients. These studies indicate that the use of azithromycin with chloroquine/hydroxychloroquine could significantly prolong QT interval, especially in patients affected by severe COVID-19 and in the presence of comorbidities, suggesting using this association with caution [62-66]. According to the Liverpool Drug Interactions group, electrocardiogram monitoring is recommended in patients treated with chloroquine/hydroxychloroquine and other QT-prolonging drugs including azithromycin [67]. No interactions are reported for other classes of antimicrobials such as penicillins or cephalosporins, which may therefore be a safer therapeutic alternative to azithromycin, even when combined with chloroquine/hydroxychloroquine.

The risks of combining torsadogenic drugs such as azithromycin and hydroxychloroquine/chloroquine were highlighted by several scientific societies or drug agencies. On 30 March 2020, the French drug safety agency (ANSM) warned of potentially serious side effects, in particular cardiac risk, of treatments being tested against the new 
Table 1 Number of individual safety case reports in Eudravigilance for serious cardiac arrhythmias during azithromycin, hydroxychloroquine and chloroquine treatments at 30 May, 2020

\begin{tabular}{lccc}
\hline & Azithromycin & Hydroxychloroquine & Chloroquine \\
\hline Overall reports in Eudravigilance & 12,764 & 15,129 & 1644 \\
Arrhythmia $^{\mathrm{a}}$ & 109 & 63 & 14 \\
Cardiac arrest & 93 & 46 & 33 \\
Torsades de pointes $_{\text {Atrioventricular block }}^{\mathrm{b}}$ & 50 & 22 & 11 \\
ECG QT prolonged & 20 & 51 & 62 \\
Long-QT syndrome & 271 & 245 & 71 \\
Ventricular fibrillation & 24 & 17 & 17 \\
\hline
\end{tabular}

$E C G$ electrocardiogram

${ }^{a}$ Includes ventricular and supraventricular arrhythmia

${ }^{\mathrm{b}}$ Includes complete atrioventricular block, first and second degree block coronavirus (hydroxychloroquine and lopinavir/ritonavir) after the deaths of three people possibly linked to self-medication. ANSM also pointed out how this cardiac risk could be increased by using hydroxychloroquine in association with other potentially torsadogenic drugs such as azithromycin, or in patients with specific metabolic disorders (e.g. hypokalaemia) [68]. The American College of Cardiology (ACC) noted that COVID-19-infected patients are likely to have longer baseline QTc and higher potential arrhythmic risks as a result of the metabolic and physiologic sequelae of their illness, and a typically greater burden of comorbid disease [69]. Recently, the ACC suggested that safety concerns regarding the use of hydroxychloroquine-azithromycin combination for COVID-19 should be considered in the context of several important mitigating factors, such as the short duration of treatment and the potential benefit among specific subgroups with COVID-19 infection (in particular, ICU-hospitalised patients with serious illness). Furthermore, the ACC highlighted that close monitoring and optimisation of known risk factors for TdP (e.g. structural heart disease, congenital long-QT syndromes, electrolyte disturbances, hepatic/renal failure, etc.) could maximise the safety of potential QT-prolonging medications [69]. Both AIFA and ACC stated that a clinical trial evaluating the effectiveness and safety of these drugs is urgently needed. Mayo Clinic has recently published its own recommendations for the treatment of COVID-19 patients with potentially arrhythmogenic drugs. This guidance suggests that it is essential to identify the small subset of patients who, either due to a genetic predisposition and/or due to QT risk factors, have a high baseline risk of QT prolongation and/ or have an inherent tendency to develop an exaggerated QT response after being treated with QT-prolonging medications [70]. Elderly patients in particular may be at higher risk, especially because of the likelihood of being prescribed QT-prolonging drugs and of polypharmacy in this population [71].

\section{Conclusion}

There is no clear evidence that azithromycin may exert beneficial effects in COVID-19 beyond antibacterial activity in bacterial superinfection. In COVID-19 infection, empirical broad-spectrum antibiotic therapy should be chosen only to treat superinfection, preferably based on CAP treatment guidelines from scientific societies, which never recommend macrolide use alone as first-line treatment. Although the arrhythmogenic potential of azithromycin is lower as compared with other macrolides or other antibacterial drug classes, such as fluoroquinolones, the use of drugs with even a low risk of arrhythmia with other potential QT-prolonging drugs such as hydroxychloroquine/chloroquine warrants close electrocardiogram monitoring. If not possible, as may be the case in an outpatient setting, a thorough evaluation of potential risk factors for arrhythmia has to be considered with the ultimate goal to carefully weigh the risks against the benefits of different antibiotics for the treatment of bacterial superinfection in COVID-19 patients.

\section{Compliance with Ethical Standards}

Funding No sources of funding were used to prepare this article.

Conflict of interest Gianluca Trifirò, has served on advisory boards for Sandoz, Hospira, Sanofi, Biogen, Ipsen and Shire; is the principal investigator of observational studies funded by several pharmaceutical companies (e.g. Amgen, AstraZeneca, Daiichi Sankyo and IBSA) to the University of Messina; and is scientific coordinator of the Master's program 'Pharmacovigilance, pharmacoepidemiology and pharmacoeconomics: real-world data evaluations' at the University of Messina, which is partly funded by several pharmaceutical companies. Janet Sultana, Paola Maria Cutroneo, Salvatore Crisafulli, Gabriele Puglisi and Gaetano Caramori have no conflicts of interest that are directly relevant to the content of this article.

Ethics approval Not applicable.

Consent to participate Not applicable. 
Consent for publication Not applicable.

Availability of data and material Data sharing is not applicable to this article as no datasets were generated or analysed during the current study.

Code availability Software application or custom code: not applicable.

Author Contributions All authors contributed equally to this work.

\section{References}

1. European Centre for Disease Prevention and Control. Situation update worldwide. 2020. https://www.ecdc.europa.eu/en/covid -19-pandemic. Accessed 25 June 2020.

2. Angus DC. Optimizing the trade-off between learning and doing in a pandemic. JAMA. 2020. https://doi.org/10.1001/ jama.2020.4984.

3. World Health Organization. WHO Clinical management of severe acute respiratory infection (SARI) when COVID-19 disease is suspected. WHO. 2020. https://www.who.int/publications/i/item/ clinical-management-of-covid-19. Accessed 1 July 2020.

4. Europan Medicines Agency. Global regulators stress need for robust evidence on COVID-19 treatments. 2020. https://www. ema.europa.eu/en/documents/press-release/global-regulators-stres s-need-robust-evidence-covid-19-treatments_en.pdf. Accessed 1 July 2020.

5. Metlay JP, Waterer GW. Treatment of community-acquired pneumonia during the Coronavirus Disease 2019 (COVID-19) Pandemic. Ann Intern Med. 2019;2020:M20-2189.

6. Du Y, Tu L, Zhu P, Mu M, Wang R, Yang P, et al. Clinical features of 85 fatal cases of COVID-19 from Wuhan: a retrospective observational study. Am J Respir Crit Care Med. 2020;201(11):1372-9.

7. Zhou F, Yu T, Du R, Fan G, Liu Y, Liu Z, et al. Clinical course and risk factors for mortality of adult inpatients with COVID19 in Wuhan, China: a retrospective cohort study. Lancet. 2020;395(10229):1054-62.

8. National Institute for Health and Care Excellence (NICE). COVID-19 rapid guideline: antibiotics for pneumonia in adults in hospital [Internet]. 2020. https://www.nice.org.uk/guidance/ ng173. Accessed 1 July 2020.

9. Pakhale S, Mulpuru S, Verheij TJM, Kochen MM, Rohde GGU, Bjerre LM. Antibiotics for community-acquired pneumonia in adult outpatients. Cochrane Database Syst Rev. 2014;2014(10):CD002109.

10. National Institute for Health and Care Excellence (NICE). Pneumonia (community-acquired): antimicrobial prescribing [Internet]. 2019. https://www.nice.org.uk/guidance/ng138. Accessed 1 July 2020

11. Huang C, Wang Y, Li X, Ren L, Zhao J, Hu Y, et al. Clinical features of patients infected with 2019 novel coronavirus in Wuhan, China. Lancet. 2020;395(10223):497-506.

12. Kanoh S, Rubin BK. Mechanisms of action and clinical application of macrolides as immunomodulatory medications. Clin Microbiol Rev. 2010;23(3):590-615.

13. Cramer CL, Patterson A, Alchakaki A, Soubani AO. Immunomodulatory indications of azithromycin in respiratory disease: a concise review for the clinician. Postgrad Med. 2017;129:493-9.

14. Parnham MJ, Haber VE, Giamarellos-Bourboulis EJ, Perletti G, Verleden GM, Vos R. Azithromycin: mechanisms of action and their relevance for clinical applications. Pharmacol Ther. 2014;143:225-45.

15. Stockman LJ, Bellamy R, Garner P. SARS: systematic review of treatment effects. PLoS Med. 2006;3(9):e343.

16. Horby P, Wei WS, Emberson J, Mafham M, Bell J, Linsell L, Staplin L, Brightling L, et al. Effect of dexamethasone in hospitalized patients with COVID-19: preliminary report. medRxiv. 2020. https://doi.org/10.1101/2020.06.22.20137273.

17. Bosseboeuf E, Aubry M, Nhan T, de Pina JJ, Rolain JM, Raoult D, et al. Azithromycin inhibits the replication of Zika virus. J Antivir Antiretrovir. 2018;10:6-11.

18. Retallack H, Di Lullo E, Arias C, Knopp KA, Laurie MT, Sandoval-Espinosa $\mathrm{C}$, et al. Zika virus cell tropism in the developing human brain and inhibition by azithromycin. Proc Natl Acad Sci USA. 2016;113:14408-13.

19. Madrid PB, Panchal RG, Warren TK, Shurtleff AC, Endsley AN, Green CE, et al. Evaluation of Ebola virus inhibitors for drug repurposing. ACS Infect Dis. 2015;1(7):317-26.

20. Gielen V, Johnston SL, Edwards MR. Azithromycin induces anti-viral responses in bronchial epithelial cells. Eur Respir J. 2010;36(3):646-54.

21. Kakeya H, Seki M, Izumikawa K, Kosai K, Morinaga Y, Kurihara $\mathrm{S}$, et al. Efficacy of combination therapy with oseltamivir phosphate and azithromycin for influenza: a multicenter, open-label, randomized study. PLoS One. 2014;9:1-10.

22. Arabi YM, Deeb AM, Al-Hameed F, Mandourah Y, Almekhlafi GA, Sindi AA, et al. Macrolides in critically ill patients with Middle East Respiratory Syndrome. Int J Infect Dis. 2019;81:184-90.

23. Gautret P, Lagier J-C, Parola P, Hoang VT, Meddeb L, Mailhe $\mathrm{M}$, et al. Hydroxychloroquine and azithromycin as a treatment of COVID-19: results of an open-label non-randomized clinical trial. Int J Antimicrob Agents. 2020. https://doi.org/10.1016/j.ijantimica g.2020.105949.

24. Molina JM, Delaugerre C, Le Goff J, Mela-Lima B, Ponscarme $\mathrm{D}$, Goldwirt L, et al. No evidence of rapid antiviral clearance or clinical benefit with the combination of hydroxychloroquine and azithromycin in patients with severe COVID-19 infection. Méd Mal Infect. 2020;50(4):384.

25. Rosenberg ES, Dufort EM, Udo T, Wilberschied LA, Kumar J, Tesoriero J, et al. Association of treatment with hydroxychloroquine or azithromycin with in-hospital mortality in patients with COVID-19 in New York state. JAMA. 2020;12203:1-10.

26. Italian Medicines Agency (AIFA). Hydroxychloroquine for the treatment of COVID-19 adult patients. 2020. https://www.aifa. gov.it/documents/20142/0/idrossiclorochina1-002_01.04.2020. pdf/5d35dbb6-c9e7-1e17-8798-92952512fdcc. Accessed 1 July 2020.

27. Vogt AW, Zollo RA. Long Q-T syndrome associated with oral erythromycin used in preoperative bowel preparation. Anesth Analg. 1997;85(5):1011-3.

28. Tschida SJ, Guay DRP, Straka RJ, Hoey LL, Johanning R, VanceBryan K. QT(c)-interval prolongation associated with slow intravenous erythromycin lactobionate infusions in critically ill patients: a prospective evaluation and review of the literature. Pharmacotherapy. 1996;16(4):663-74.

29. De Ponti F, Poluzzi E, Montanaro N. QT-interval prolongation by non-cardiac drugs: Lessons to be learned from recent experience. Eur J Clin Pharmacol. 2000;56(1):1-18.

30. Drici MD, Knollmann BC, Wang WX, Woosley RL. Cardiac actions of erythromycin: Influence of female sex. J Am Med Assoc. 1998;280(20):1774-6.

31. Shaffer D, Singer S, Korvick J, Honig P. Concomitant risk factors in reports of torsades de pointes associated with macrolide use: review of the United States Food and Drug Administration Adverse Event Reporting System. Clin Infect Dis. 2002;35(2):197-200. 
32. Koh TW. Risk of torsades de pointes from oral erythromycin with concomitant carbimazole (Methimazole) administration. PACE Pacing Clin Electrophysiol. 2001;24(10):1575-6.

33. Goldstein EJC, Owens RC, Nolin TD. Antimicrobial-associated QT interval prolongation: pointes of interest. Clin Infect Dis. 2006;43(12):1603-11.

34. Fossa AA, Wisialowski T, Duncan JN, Deng S, Dunne M. Azithromycin/chloroquine combination does not increase cardiac instability despite an increase in monophasic action potential duration in the anesthetized guinea pig. Am J Trop Med Hyg. 2007;77(5):929-38.

35. Milberg P, Eckardt L, Bruns HJ, Biertz J, Ramtin S, Reinsch N, et al. Divergent proarrhythmic potential of macrolide antibiotics despite similar QT prolongation: fast phase 3 repolarization prevents early afterdepolarizations and torsade de pointes. J Pharmacol Exp Ther. 2002;303:218-25.

36. Thomsen MB, Beekman JDM, Attevelt NJM, Takahara A, Sugiyama A, Chiba K, et al. No proarrhythmic properties of the antibiotics moxifloxacin or azithromycin in anaesthetized dogs with chronic-AV block. Br J Pharmacol. 2006;149:1039-48.

37. Grayston JT, Kronmal RA, Jackson LA, Parisi AF, Muhlestein $\mathrm{JB}$, Cohen JD, et al. Azithromycin for the secondary prevention of coronary events. N Engl J Med. 2005;352:1637-45.

38. Baker WL, Couch KA. Azithromycin for the secondary prevention of coronary artery disease: a meta-analysis. Am J Heal Pharm. 2007;64:830-6.

39. Almalki ZS, Guo JJ. Cardiovascular events and safety outcomes associated with azithromycin. Am Heal Drug Benefits. 2014;7(6):318-28.

40. Matsunaga N, Oki Y, Prigollini A. A case of QT-interval prolongation precipitated by azithromycin. $\mathrm{N} Z \mathrm{Z}$ Med J. 2003;116(1185):U666.

41. Samarendra P, Kumari S, Evans SJ, Sacchi TJ, Navarro V. QT prolongation associated with azithromycin/amiodarone combination. PACE Pacing Clin Electrophysiol. 2001;24(10):1572-4.

42. Russo V, Puzio GF, Siniscalchi N. Azithromycin-induced QT prolongation in elderly patient. Gazz Medica Ital Arch per le Sci Mediche. 2006;77(1):30-2.

43. Arellano-Rodrigo E, García A, Mont L, Roqué M. Torsade de pointes and cardiorespiratory arrest induced by azithromycin in a patient with congenital long QT syndrome. Med Clin (Barc). 2001;117:118-9.

44. Kezerashvili A, Khattak H, Barsky A, Nazari R, Fisher JD. Azithromycin as a cause of QT-interval prolongation and torsade de pointes in the absence of other known precipitating factors. J Interv Card Electrophysiol. 2007;18(3):243-6.

45. Huang BH, Wu CH, Hsia CP, Yin Chen C. Azithromycininduced torsade de pointes. PACE Pacing Clin Electrophysiol. 2007;30(12):1579-82.

46. Kim MH, Berkowitz C, Trohman RG. Polymorphic ventricular tachycardia with a normal QT interval following azithromycin. PACE Pacing Clin Electrophysiol. 2005;28(11):1221-2.

47. Yang Z, Prinsen JK, Bersell KR, Shen W, Yermalitskaya L, Sidorova T, et al. Azithromycin causes a novel proarrhythmic syndrome. Circ Arrhythm Electrophysiol. 2017;10(4):e003560.

48. Poluzzi E, Raschi E, Motola D, Moretti U, De Ponti F. Antimicrobials and the risk of torsades de pointes: the contribution from data mining of the US FDA adverse event reporting system. Drug Saf. 2010;33(4):303-14.

49. Ray WA, Murray KT, Hall K, Arbogast PG, Stein CM. Azithromycin and the risk of cardiovascular death. N Engl J Med. 2012;366(20):1881-90.

50. Food and Drug Administration. FDA drug safety communication: azithromycin (Zithromax or Zmax) and the risk of potentially fatal heart rhythms. 2013. https://www.fda.gov/media /85787/download. Accessed 1 July 2020.
51. Svanström H, Pasternak B, Hviid A. Use of azithromycin and death from cardiovascular causes. N Engl J Med. 2013;368(18):1704-12.

52. Rao GA, Mann JR, Shoaibi A, Bennett CL, Nahhas G, Sutton SS, et al. Azithromycin and levofloxacin use and increased risk of cardiac arrhythmia and death. Ann Fam Med. 2014;12(2):121-7.

53. Hinkle LE, Thaler HT. Clinical classification of cardiac deaths. Circulation. 1982;65(3):457-64.

54. Marcus FI, Cobb LA, Edwards JE, Kuller L, Moss AJ, Bigger JT, et al. Mechanism of death and prevalence of myocardial ischemic symptoms in the terminal event after acute myocardial infarction. Am J Cardiol. 1988;61(1):8-15.

55. Mortensen EM, Halm EA, Pugh MJ, Copeland LA, Metersky M, Fine MJ, et al. Association of azithromycin with mortality and cardiovascular events among older patients hospitalized with pneumonia. JAMA J Am Med Assoc. 2014;311(21):2199-208.

56. Trac MH, McArthur E, Jandoc R, Dixon SN, Nash DM, Hackam DG, et al. Macrolide antibiotics and the risk of ventricular arrhythmia in older adults. CMAJ. 2016;188(7):E120-9.

57. Chou HW, Wang JL, Chang CH, Lai CL, Lai MS, Chan KA. Risks of cardiac arrhythmia and mortality among patients using new-generation macrolides, fluoroquinolones, and $\beta$-lactam $/ \beta$ lactamase inhibitors: a Taiwanese nationwide study. Clin Infect Dis. 2015;60(4):566-77.

58. Polgreen LA, Riedle BN, Cavanaugh JE, Girotra S, London $\mathrm{B}$, Schroeder MC, et al. Estimated cardiac risk associated with macrolides and fluoroquinolones decreases substantially when adjusting for patient characteristics and comorbidities. J Am Heart Assoc. 2018;7(9):e008074.

59. Trifirò G, De Ridder M, Sultana J, Oteri A, Rijnbeek P, Pecchioli $\mathrm{S}$, et al. Use of azithromycin and risk of ventricular arrhythmia. CMAJ. 2017;189(15):E560-8.

60. CredibleMeds. Recommendations re: COVID-19 Treatments. 2020. https://www.crediblemeds.org/blog/recommendations-reCOVID-19-treatments/.

61. Saleh M, Gabriels J, Chang D, Kim BS, Mansoor A, Mahmood E, et al. The effect of chloroquine, hydroxychloroquine and azithromycin on the corrected QT interval in patients with SARS-CoV-2 infection. Circ Arrhythm Electrophysiol. 2020;13(6):e008662.

62. Chorin E, Dai M, Shulman E, Wadhwani L, Bar-Cohen R, Barbhaiya C, et al. The QT interval in patients with COVID-19 treated with hydroxychloroquine and azithromycin. Nat Med. 2020;26(6):808-9.

63. Lane JCE, Weaver J, Kostka K, Duarte-Salles T, Abrahao MTF, Alghoul H, Alser O, et al. Safety of hydroxychloroquine, alone and in combination with azithromycin, in light of rapid widespread use for COVID-19: a multinational, network cohort and self-controlled case series study. medRxiv. 2020. https://doi. org/10.1101/2020.04.08.20054551.

64. Cipriani A, Zorzi A, Ceccato D, Capone F, Parolin M, Donato F, et al. Arrhythmic profile and 24-hour QT interval variability in COVID-19 patients treated with hydroxychloroquine and azithromycin. Int J Cardiol. 2020. https://doi.org/10.1016/j.ijcar d.2020.05.036.

65. Mercuro NJ, Yen CF, Shim DJ, Maher TR, McCoy CM, Zimetbaum PJ, et al. Risk of QT interval prolongation associated with use of hydroxychloroquine with or without concomitant azithromycin among hospitalized patients testing positive for coronavirus disease 2019 (COVID-19). JAMA Cardiol. 2019;2020:e201834.

66. Gérard A, Romani S, Fresse A, Viard D, Parassol N, Granvuillemin A, et al. "Off-label" use of hydroxychloroquine, azithromycin, lopinavir-ritonavir and chloroquine in COVID-19: a survey of cardiac adverse drug reactions by the French Network of Pharmacovigilance Centers. Therapies. 2020;S0040-5957(20):30091-3. 
67. Liverpool Drug Interactions Group. Interactions with Experimental COVID-19 Therapies. 2020. https://liverpool-covid19.s3.euwest-2.amazonaws.com/35ts8mgxj07kudl14ay87814k57o?respo nse-content-disposition=inline $\% 3 \mathrm{~B}$ filename $\% 3 \mathrm{D} \% 22 \mathrm{Cov}$ id_InteractionDetails_Web_2020_Apr_09.pdf\%22\%3Bfilename \%2A\%3DUTF-8\%27\%27Covid_InteractionDetails_Web_2020_ Apr_09.pdf. Accessed 1 July 2020.

68. Agence nationale de sécurtité du mèdicament et des produits de santé. Hydroxychloroquine. Infection par le coronavirus SARSCoV-2 (maladie COVID-19). 2020; https://www.ansm.sante.fr/ var/ansm_site/storage/original/application/bb638dd13cfe387 9c3d04b6081d57315.pdf. Accessed 1 July 2020.

69. American College of Cardiology. Ventricular Arrhythmia Risk Due to Hydroxychloroquine-Azithromycin Treatment For
COVID-19. 2020. https://www.acc.org/latest-in-cardiology/artic les/2020/03/27/14/00/ventricular-arrhythmia-risk-due-to-hydro xychloroquine-azithromycin-treatment-for-COVID-19. Accessed 1 July 2020.

70. Giudicessi JR, Noseworthy PA, Friedman PA, Ackerman MJ. Urgent guidance for navigating and circumventing the QTc prolonging and torsadogenic potential of possible pharmacotherapies for COVID-19. Mayo Clin Proc. 2020;95(6):1213-21.

71. Schächtele S, Tümena T, Gaßmann KG, Fromm MF, Maas R. Coprescription of QT-interval prolonging drugs: an analysis in a large cohort of geriatric patients. PLoS One. 2016;11(5):e0155649. 